D. BRUCE: What defences may be used to prevent frost heaving, in particular for highways with asphalt pavement?

Kinosita: Soil which is susceptible to strong frost-heaving action is replaced by other materials which have a coarse grain (e.g. sand). The depth of such replacement is $80 \%$ of maximum frost penetration. Furthermore replacement is limited only to $40 \mathrm{~cm}$ below the pavement surface. Under the $40 \mathrm{~cm}$ level a board of thermal insulation, such as polystyrene is placed. The thickness of the insulation depends on the severity of the frost.

\title{
GHARACTERISTICS OF PROCESSES OF ELECTRICAL RELAXATION IN FROZEN SOILS
}

\author{
By A. D. Frolov and B. V. Gusev \\ (Moscow Geological Prospecting Institute, Moscow, U.S.S.R.)
}

Aвstract. The results of measurements of dielectric properties of frozen soils are analysed on the basis of modified theory of dielectrics. The relaxational character of frequency and temperature dependence is shown and the basic equations are derived. The characteristics of distribution of relaxation times and effective relaxation times as depending on the temperatures are discussed. The values of activation energy are estimated. 